\title{
EVALUATION OF EFFECT OF BILATERAL TOTAL SALPINGECTOMY ON OVARIAN FUNCTION AMONG PRE-MENOPAUSAL WOMEN UNDERGOING ABDOMINAL HYSTERECTOMY
}

\author{
Sukumar Mitra1, Faraz Vali², Parul Choudhary33, Aprateem Mukherjee 4 \\ ${ }^{1}$ Associate Professor, Department of Obstetrics and Gynaecology, Medical College and Hospital, Kolkata. \\ ${ }^{2}$ Resident, Department of Obstetrics and Gynaecology, Medical College and Hospital, Kolkata. \\ ${ }^{3}$ Resident, Department of Obstetrics and Gynaecology, Medical College and Hospital, Kolkata. \\ ${ }^{4}$ Resident, Department of Radiodiagnosis, Medical College and Hospital, Kolkata.
}

ABSTRACT

\section{BACKGROUND}

Hysterectomy is a widely performed surgery. Whether bilateral salpingectomy done along with Total Abdominal Hysterectomy (TAH) affect ovarian function is controversial. This study aims to find out if bilateral salpingectomy has any adverse effect on the ovarian health.

\section{MATERIALS AND METHODS}

Patients were allotted into 2 groups based on their preference. Each group had 30 patients. One group underwent Total Abdominal Hysterectomy with Bilateral Total Salpingectomy (TAH-BLS) and the other underwent TAH alone. Preoperatively, Kupperman Index (KI) was calculated based on detailed history of symptoms regarding menopause, serum Follicular Stimulating Hormone level (FSH) was measured and bilateral ovarian volume was assessed using TVS. Patients were followed up at 3 months and 6 months postoperatively and KI, serum FSH and bilateral ovarian volume were assessed.

\section{RESULTS}

The outcome (that is change or 'delta' or ' $\Delta$ ') for all four variables (KI, FSH, ovarian volume on right side and left side) showed positive changes at 3 months as well as at 6 months in each group. For testing the significance of the changes in variables in each group, paired T-test was applied and it was found that all the changes in KI and FSH at 3 months as well as at 6 months were statistically insignificant, while there was significant rise in ovarian volume at 3 months in both the groups which became insignificant at end of 6 months. On comparing the two groups using the unpaired T-test, the changes i.e. rise in all the variables were more in the Group A than Group B, but there was no significant difference between the two groups with respect to changes in KI, FSH levels or ovarian volumes.

\section{CONCLUSION}

At the end of 6 months postoperatively, there was no significant rise in the KI, FSH levels and ovarian volumes in the group undergoing TAH with salpingectomy and there was no significant difference between the two groups with respect to each variable. So we conclude that salpingectomy does not significantly affect the function of the intact ovaries after TAH-BLS.

\section{KEYWORDS}

Total Abdominal Hysterectomy with Bilateral Total Salpingectomy (TAH-BLS), Kupperman Index, High Grade Serous Carcinoma.

HOW TO CITE THIS ARTICLE: Mitra S, Vali F, Choudhary P, et al. Evaluation of effect of bilateral total salpingectomy on ovarian function among pre-menopausal women undergoing abdominal hysterectomy. J. Evolution Med. Dent. Sci. 2017;6(34):2833-2839, DOI: $10.14260 /$ Jemds/2017/609

\section{BACKGROUND}

Hysterectomy is a widely performed surgery in women of pre-menopausal and menopausal age group. TAH with bilateral salpingo-oophorectomy (TAH-BSO) definitely leads to surgical menopause, but whether TAH with preservation of ovaries and tubes or TAH with bilateral salpingectomy leads to or accelerates menopause is controversial.

Conventionally, in premenopausal women the recommended surgery was standard TAH with preservation of adnexa. Recently, there is a growing evidence to suggest that many if not most, High-Grade Serous Cancer (HGSC)

Financial or Other, Competing Interest: None.

Submission 22-03-2017, Peer Review 14-04-2017,

Acceptance 21-04-2017, Published 27-04-2017.

Corresponding Author:

Dr. Faraz Vali,

Amar Prem, Machchi Bunglow Area,

Oppo. Gymkhana, Civil lines,

Godhra-389001, Gujarat.

E-mail:farazvali@gmail.com

DOI: $10.14260 /$ jemds $/ 2017 / 609$

\section{(c) $(1)$}

arise from the fimbrial end of the fallopian tube rather than from the ovary. ${ }^{1,2}$ HGSC (i.e. type 2) are considered rapidly growing, highly aggressive, genetically unstable and often disseminated kind of disease. One of the more important finding in last decade of gynaecologic oncology is the confirmed theory that type II tumours derive from the epithelium of the fallopian tube, whereas clear cell and endometrioid tumours derive from endometrial tissue that migrate to the ovary by retrograde menstruation. ${ }^{3}$ These observations are mainly collected from women that carry BRCA 1/2 mutations and underwent prophylactic salpingooophorectomy, in which most of the incidentally diagnosed in situ carcinomas or intraepithelial precursors of cancers (STIC) were detected not in the ovary but in the fimbrial end of the fallopian tube.4-6 Thus, the new preventive strategy based on prophylactic salpingectomy at the time of surgery for benign pathologies seems beneficial.

But various studies have proved that unilateral or bilateral removal of the fallopian tubes may have a detrimental effect on the ovarian arterial supply. Salpingectomy that is not properly performed close to the 
tube may disrupt the normal blood flow to the ovary. This may have a negative impact on steroid production and further follicular development. There is a theoretical possibility of development of surgical menopause and longterm increased risk of cardiovascular diseases, hip fracture, cognitive disorders, etc.

Therefore, bilateral salpingectomy with ovarian preservation should be considered in a cost-benefit analysis. This study aims at to find out whether bilateral salpingectomy has any adverse effect on the ovarian health.

\section{Objectives}

1. To study clinical effects (Kupperman Index), changes in hormone level (serum FSH) and ovarian volume after total salpingectomy.

2. To statistically examine intragroup and intergroup clinical, hormonal and ovarian volume changes.

\section{MATERIALS AND METHODS}

This is a non-randomised interventional study. It was conducted at Department of Obstetrics and Gynaecology, Medical College and Hospital from 1st June 2015 to 31st August 2016; 60 patients were enrolled. Patients included were age $\leq 45$ years, not yet achieved menopause with benign conditions of uterus and ovaries requiring only hysterectomy. Benign conditions involved fibroid uterus, menorrhagia and chronic pain in lower abdomen. We excluded patients with age $>45$ years, having a family history of ovarian cancer, basal FSH value of $>20 \mathrm{IU} / \mathrm{L}$, presence of menopausal symptoms, history of hormone replacement treatment and/or hormonal contraception for the last 3 months, history of previous ovarian surgeries, history of imaging suggestive of ovarian cyst or tubal pathology at transvaginal ultrasound or with other gynaecological problems indicating alternative surgery such as endometriosis or ovarian masses. The procedures followed were in accordance with the Helsinki Declaration of 1975 that was revised in 2000.

Patients were allotted into 2 groups based on their preference. Each group had 30 patients. Patients in Group A underwent TAH and complete excision of the fallopian tubes bilaterally. In Group B, all patients had been subjected to TAH with preservation of bilateral fallopian tubes along with ovaries. We took detailed history of each patient preoperatively, 3 months and 6 months postoperative and Kupperman Index (KI) ${ }^{7,8}$ was applied. The $\mathrm{KI}$ is a numerical conversion index. It is used to quantify the menopausal symptoms. It consists of 11 symptoms (Table 1): Hot flushes, palpitation, vertigo, headache, paraesthesia, formication, arthralgia and myalgia; categorised as somatic symptoms and insomnia, fatigue, nervousness and melancholia; categorised as psychological symptoms. A scale ranging from 0 to 3 points is used to describe the severity of the complaints. According to severity: 0 , no symptoms; 1 , mild symptoms; 2 , moderate symptoms; and 3 , severe symptoms. The weighting factor for hot flushes or sweating is 4; paraesthesia, insomnia and nervousness are given a weightage of 2 each; and all other symptoms 1 each. Weighted score $=$ raw score $\times$ weighting factor. The maximum score is 51 points. Classification of the Kupperman Index is "no complaint" (total score 0 - 6), "mild" (total score 7 - 19), "moderate" (total score 20 - 35) or "severe" (Total score $>35$ ).
Similarly, Follicle Stimulating Hormone (FSH, IU/L) levels were evaluated three times, each time during the early follicular phase. After hysterectomy, due to the absence of menstrual flow, patients were instructed to identify their early follicular phase by consulting their past menstrual diary and recognising the rapid decrease of self-reported "fluid retention" impression, indicated by a feeling of bloating, oedema and/or nocturia, in the days of the expected menses ${ }^{9}$ and was confirmed by the absence of both a dominant follicle and corpus luteum on TVS. Blood samples were obtained by venepuncture and centrifuged within 30 mins of collection to separate the serum. Each serum underwent subsequent analysis of FSH.

Ovarian volume was assessed preoperatively and 3 and 6 months postoperatively during the early follicular phase by the same radiologist using Philips ClearVue 550 with 2 to 5 $\mathrm{MHz}$ probe. Measures included Transverse (T), AnteroPosterior (AP) and Longitudinal (L) diameters of ovaries and Volume (V) was estimated using the formula $\mathrm{V}$ (Cubic centimetres $)=\mathrm{T}$ (Centimetres) $\times \mathrm{AP}$ (Centimetres) $\times \mathrm{L}$ (Centimetres) $\times 0.52$.

Analysis was performed in Microsoft Excel 2013, using student paired as well as unpaired T-test. Significance level was set at $5 \%$. Considering 6-month post-operative serum FSH values from a previous study (Sezik Mekin et al, 2007), keeping $\alpha$-error of 1.96 and power of study at $80 \%$, our sample size calculated was 37 in each group, but in our short study period we had to restrict sample size up to 30 per group.

\section{RESULTS}

From 1st June 2015 to 31st August 2016, 60 patients were enrolled and were allotted in 2 groups of 30 each. Among all study participants, the mean age was $41.4 \pm 5.47$ years and the mean parity was $2.78 \pm 1.73$. The mean age and parity in Group A was $40.5 \pm 15.8$ years and $2.6 \pm 2.1$ respectively, while in Group B mean age was $42.23 \pm 3.9$ years and mean parity was $2.93 \pm 1.4$. In Group A pre-operative mean KI, FSH and ovarian volume right and left side were $2.16 \pm 6.4,5.8 \pm$ $10.5 \mathrm{IU} / \mathrm{L}, 3.8 \pm 4.4 \mathrm{~cm}^{3}, 3.1 \pm 5 \mathrm{~cm}^{3}$ respectively, while in Group B pre-operative mean KI, FSH and ovarian volume right and left side were $4.3 \pm 10,6.5 \pm 9.1 \mathrm{IU} / \mathrm{L}, 2.3 \pm 2.6 \mathrm{~cm}^{3}$ and $2.8 \pm 4.2 \mathrm{~cm}^{3}$ respectively. There were no substantial differences in the baseline characteristics of the two groups (Table 2). Indications for hysterectomy were fibroid (55\%), Dysfunctional Uterine Bleeding (DUB) (28.33\%), adenomyosis $(10 \%)$ and chronic lower abdominal pain (6.66\%) (Table 3).

The outcome (that is change or 'delta' or ' $\Delta$ ') for the four variables $(\Delta \mathrm{KI}, \Delta \mathrm{FSH}, \Delta$ Ovarian volume on right side and left side) at 3 months for Group A and Group B are shown in Table 4 and the changes at 6 months are shown in Table 5. All the variables showed positive changes at 3 months as well as at 6 months. Paired T-test was applied to test significance in each group. All the changes in KI and FSH at 3 months as well as at 6 months were statistically insignificant, while there was significant rise in ovarian volume at 3 months in both the groups which became insignificant at the end of 6 months. We also did a comparison between the two groups using the Unpaired T-test as shown in Table 6. Following inferences were derived, 
1. The changes, i.e. rise in all the variables were more in Group A than Group B.

2. There was no significant difference between the two groups with respect to changes in KI, FSH levels or ovarian volumes.
The comparison between the two groups with respect to each variable is graphically depicted in Charts 1, 2, 3 and 4.

\begin{tabular}{|c|c|c|c|c|c|c|c|}
\hline \multicolumn{8}{|c|}{ Which of the following symptoms apply to you at this time? } \\
\hline \multirow[b]{2}{*}{ Symptoms } & \multirow[b]{2}{*}{$\begin{array}{l}\text { Weighting } \\
\text { Factor }\end{array}$} & \multicolumn{4}{|c|}{ Severity Scale } & \multicolumn{2}{|c|}{ Score } \\
\hline & & $\mathbf{0}$ & 1 & $x^{2}=0$ & 3 & $\begin{array}{c}\text { Raw } \\
\text { Score }\end{array}$ & $\begin{array}{l}\text { Weighted } \\
\text { Score }\end{array}$ \\
\hline $\begin{array}{c}\text { Sweating } \\
\text { Hot Flushes }\end{array}$ & $\times 4$ & None & $<3$ times/day & 3 - 9 times/day & $\geq 10$ times/day & & \\
\hline Paraesthesia & $\times 2$ & None & $\begin{array}{l}\text { Relationship } \\
\text { with climate }\end{array}$ & $\begin{array}{l}\text { Feel tingling, burning, } \\
\text { pricking or } \\
\text { numbness frequently }\end{array}$ & $\begin{array}{l}\text { Lose sense of } \\
\text { warm and pain }\end{array}$ & & \\
\hline Insomnia & $\times 2$ & None & Once in a while & $\begin{array}{c}\text { Frequent need of } \\
\text { sleeping pill }\end{array}$ & Affects life and work & & \\
\hline Nervousness & $\times 2$ & None & Once in a while & Frequent & $\begin{array}{l}\text { Frequent, cannot } \\
\text { control }\end{array}$ & & \\
\hline Melancholia & $\times 1$ & None & Once in a while & $\begin{array}{c}\text { Frequent, } \\
\text { can self-control }\end{array}$ & Losing faith in life & & \\
\hline Vertigo & $\times 1$ & None & Once in a while & Frequent & Affects daily life & & \\
\hline Fatigue & $\times 1$ & None & Once in a while & $\begin{array}{l}\text { Feel difficult when } \\
\text { climbing the } 4^{\text {th }} \text { floor }\end{array}$ & Affects daily life & & \\
\hline $\begin{array}{l}\text { Arthralgia, } \\
\text { myalgia }\end{array}$ & $\times 1$ & None & Once in a while & $\begin{array}{c}\text { Frequent, not } \\
\text { affecting function }\end{array}$ & Affects function & & \\
\hline Headache & $\times 1$ & None & Once in a while & Frequent & Requires treatment & & \\
\hline $\begin{array}{c}\text { Heart } \\
\text { Palpitation }\end{array}$ & $\times 1$ & None & Once in a while & $\begin{array}{c}\text { Frequent, not } \\
\text { affecting daily life }\end{array}$ & Requires treatment & & \\
\hline Formication & $\times 1$ & None & Once in a while & Frequent & Requires treatment & & \\
\hline & & able 1. & ptoms included & upperman Index an & eir Weightage & & \\
\hline
\end{tabular}

\begin{tabular}{|c|c|c|}
\hline & $\begin{array}{c}\text { Group A TAH } \\
\text { BLS (n = 30) }\end{array}$ & $\begin{array}{c}\text { Group B } \\
\text { TAH (n = 30) }\end{array}$ \\
\hline Age & $40.5 \pm 15.8$ & $42.23 \pm 3.9$ \\
\hline Parity & $2.6 \pm 2.1$ & $2.93 \pm 1.4$ \\
\hline KI & $2.16 \pm 6.4$ & $4.3 \pm 10$ \\
\hline FSH & $5.8 \pm 10.5$ & $6.5 \pm 9.1$ \\
\hline Ovarian Volume (Right) & $3.8 \pm 4.4$ & $2.3 \pm 2.6$ \\
\hline Ovarian Volume (Left) & $3.1 \pm 5$ & $2.8 \pm 4.2$ \\
\hline \multicolumn{2}{|c|}{ Table 2. Mean Age, Parity, Pre-Operative KI, hormone } \\
level and Ovarian Volume in Groups Under Study \\
\hline
\end{tabular}

All data expressed as mean $\pm 2 \mathrm{SD}$.

\begin{tabular}{|c|c|c|}
\hline Indications & Number of Patients & (\%) \\
\hline Fibroid & 33 & 55 \\
\hline DUB & 17 & 28.33 \\
\hline Adenomyosis & 6 & 10 \\
\hline Chronic pelvic pain & 4 & 6.66 \\
\hline \multicolumn{2}{|c|}{ Table 3. Indications for Hysterectomy in the Study Groups } \\
\hline
\end{tabular}

DUB- Dysfunctional Uterine Bleeding.

\begin{tabular}{|c|c|c|c|c|}
\hline & \multicolumn{2}{|c|}{$\begin{array}{c}\text { Group A } \\
\text { (TAH-BLS) } \mathbf{n}=\mathbf{3 0}\end{array}$} & \multicolumn{2}{c|}{$\begin{array}{c}\text { Group B } \\
\text { (TAH) } \mathbf{~ n = 3 0}\end{array}$} \\
\hline & Change & P value & Change & P value \\
\hline$\Delta$ KI & $+6.46 \pm 6$ & $>0.05$ & $+4.93 \pm 6$ & $>0.05$ \\
\hline$\Delta$ FSH & $+4.84 \pm 2.3$ & $>0.05$ & $+2.34 \pm 1.2$ & $>0.05$ \\
\hline $\begin{array}{c}\Delta \text { Ovarian } \\
\text { Volume (Right) }\end{array}$ & $+0.54 \pm 0.8$ & $\leq 0.05$ & $+0.26 \pm 0.4$ & $\leq 0.05$ \\
\hline $\begin{array}{c}\Delta \text { Ovarian } \\
\text { Volume (Left) }\end{array}$ & $\begin{array}{c}+0.50 \\
\pm 0.7\end{array}$ & $<0.05$ & $+0.23 \pm 0.4$ & $\leq 0.05$ \\
\hline
\end{tabular}

Table 4. Changes in KI, Ovarian Volume and FSH at 3 months Postoperatively among the Study Groups

All data expressed as mean change \pm SD.

\begin{tabular}{|c|c|c|c|c|}
\hline & \multicolumn{2}{|c|}{$\begin{array}{c}\text { Group A } \\
\text { (TAH-BLS) } \mathbf{n} \mathbf{3 0}\end{array}$} & \multicolumn{2}{c|}{$\begin{array}{c}\text { Group B } \\
\text { (TAH) } \mathbf{n}=\mathbf{3 0}\end{array}$} \\
\hline & Change & P value & Change & P value \\
\hline$\Delta \mathrm{KI}$ & $+12.96 \pm 7.7$ & $>0.05$ & $+7.23 \pm 7$ & $>0.05$ \\
\hline$\Delta \mathrm{FSH}$ & $+10.48 \pm 2.1$ & $>0.05$ & $+2.52 \pm 0.34$ & $>0.05$ \\
\hline $\begin{array}{c}\Delta \text { Ovarian } \\
\text { Volume } \\
\text { (Right) }\end{array}$ & +0.76 & $\leq 0.05$ & $+0.37 \pm 0.46$ & $>0.05$ \\
\hline $\begin{array}{c}\Delta \text { Ovarian } \\
\text { Volume } \\
\text { (Left) }\end{array}$ & $\begin{array}{c} \pm 0.94 \\
\text { Table 5. Changes in KI, Ovarian Volume and FSH at 6 } \\
\text { months Postoperatively among the Study Groups }\end{array}$ \\
\hline
\end{tabular}

All data expressed as mean change \pm SD. 


\begin{tabular}{|c|c|c|c|c|c|c|}
\hline & \multicolumn{3}{|c|}{$\begin{array}{l}\text { Change between } 3 \text { months } \\
\text { and Preoperative Values }\end{array}$} & \multicolumn{3}{|c|}{$\begin{array}{l}\text { Change between } 6 \text { months } \\
\text { and Preoperative Values }\end{array}$} \\
\hline & $\begin{array}{c}\text { Group A } \\
\text { (TAH-BLS) } n=30\end{array}$ & $\begin{array}{c}\text { Group B } \\
(\mathrm{TAH}) \mathrm{n}=\mathbf{3 0}\end{array}$ & & $\begin{array}{c}\text { Group A } \\
\text { (TAH-BLS) } n=30\end{array}$ & $\begin{array}{c}\text { Group B } \\
\text { (TAH) } n=30\end{array}$ & \\
\hline & $\Delta(\%$ change $)$ & $\Delta(\%$ change $)$ & $P$ value & $\Delta(\%$ change $)$ & $\Delta(\%$ change $)$ & $P$ value \\
\hline KI & $+6.46(74.88)$ & $+4.93(53.04)$ & $>0.05$ & $+12.96(85.67)$ & $+7.23(62.35)$ & $>0.05$ \\
\hline FSH & $+4.84(45.53)$ & $+2.34(64.41)$ & $>0.05$ & $+10.48(26.47)$ & $+2.52(27.93)$ & $>0.05$ \\
\hline Ovarian Volume (Right) & $+0.54(12.63)$ & $+0.26(10.01)$ & $>0.05$ & $+0.76(16.73)$ & $+0.37(13.61)$ & $>0.05$ \\
\hline Ovarian Volume (Left) & $+0.50(13.77)$ & $+0.23(7.86)$ & $>0.05$ & $+0.94(22.98)$ & $+0.52(15.81)$ & $>0.05$ \\
\hline
\end{tabular}

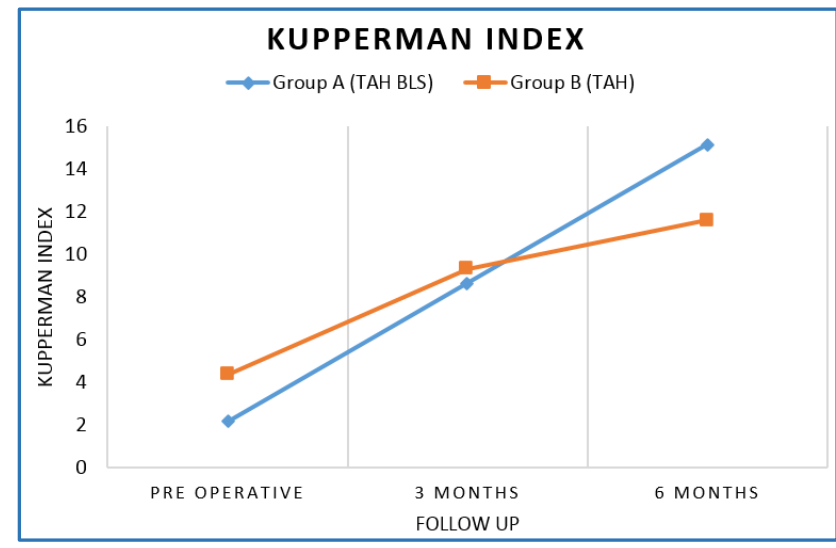

Chart 1. Changes in the Kupperman Index in Both the Groups at 3 months and 6 months Postoperatively

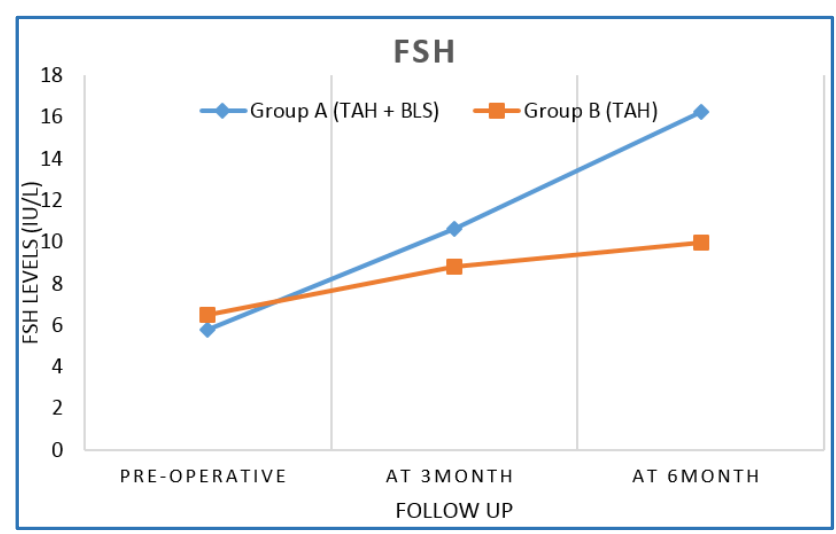

Chart 2. Changes in the FSH Levels in Both the Groups at 3 months and 6 months Postoperatively

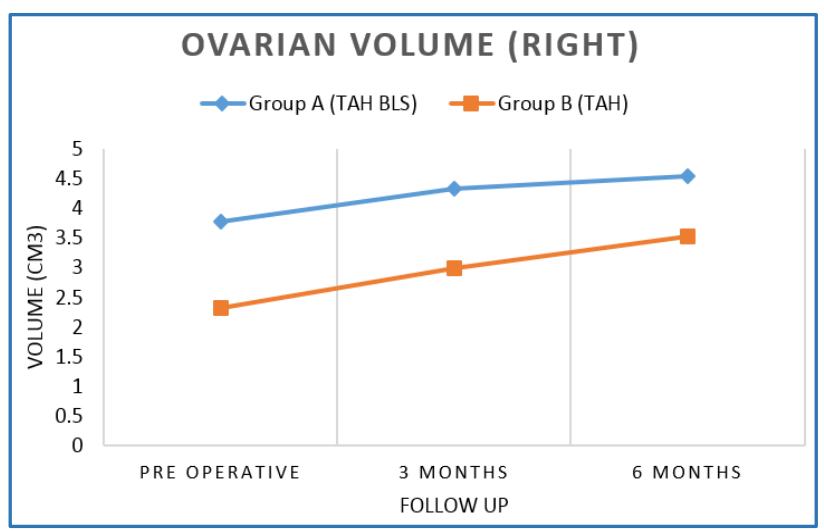

Chart 3. Changes in the Right Side Ovarian Volume in Both the Groups at 3 months and 6 months Postoperatively

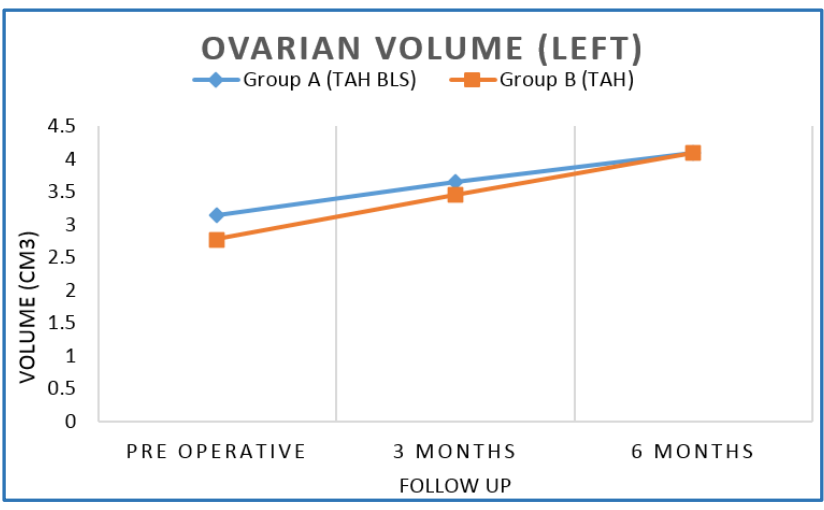

Chart 4. Changes in the Left Side Ovarian Volume in Both the Groups at 3 months and 6 months Postoperatively

\section{DISCUSSION}

Effects of salpingectomy during hysterectomy on ovarian function remains a controversial issue. This study has focused on 3 aspects of ovarian health: Clinical (Kupperman Index), Biochemical (S. FSH) and Anatomical (Ovarian volume). We have found that there was insignificant increase in all the three variables in both the groups and there was no significant difference between the two groups, which implies that salpingectomy does not affect the ovarian health. Strength of the study was the inclusion of clinical symptoms in the form of Kupperman Index, while the limitations were small sample size and short followup. Rise in Kupperman Index and S. FSH in our study can be explained as following:

1. The ovarian function, i.e. hormone production depends on the ovarian blood supply. ${ }^{10,11}$

2. The most important blood supply to the fallopian tube is the medial tubal artery, which originates at the same point as the median ovarian artery. If the salpingectomy procedure is not properly performed close to the tube, it may disrupt the normal blood flow to the ovary. ${ }^{12}$

3. The ovarian artery forms an arcade-like anastomosis system with the tubal branch of the uterine artery at the junction of the mesosalpinx and the mesovary, close to the hilum of the ovary and inadvertent injuries in this area can undoubtedly jeopardise the ovarian arterial blood supply ${ }^{13}$ and in turn it can disrupt follicular development and normal steroidal production.

Ovarian volume is generally viewed as an insensitive marker in this respect, as it may require years for such a difference to be clinically evident. ${ }^{12}$ The increase in the ovarian volume in both the groups in our study can be explained by various previous studies. Study by Elinia et al $^{14}$ showed that "a significant increase in ovarian volume was observed 6 and 12 months after TAH. Flow elevation as 
shown by the reduction in the PI (Pulsatility Index), is likely to reflect the larger size of the ovaries after the surgery." Nouh A et $\mathrm{al}^{15}$ in their study found a significant increase in ovarian blood flow in both groups (TAH-BLS and standard TAH) 6 months postoperatively reflected by decrease in RI and PI values. Ovarian volume was significantly higher 12 months postoperatively in Group I, who underwent total excision of the tube.

The rise in the three variables in Group B that underwent only hysterectomy reflects that hysterectomy does affect the ovarian health and this can be explained by following hypotheses:

1. The uterus inhibits follicle depletion and its surgical removal at reproductive age would accelerate follicular loss suggesting a paracrine effect of the uterus, endometrium or both on ovarian function. ${ }^{16}$

2. The increased prevalence of ovarian failure after hysterectomy would result from the stretching of the vessels within the pelvic infundibulum, followed by thrombosis and a reduction in ovarian blood supply. ${ }^{17-19}$

Deng et $\mathrm{al}^{20}$ concluded that hysterectomy with the conservation of bilateral/unilateral ovaries may have some influence on the ovarian function; also Ahn et al ${ }^{21}$ concluded that total abdominal hysterectomy accelerates ovarian dysfunction and women treated with total abdominal hysterectomy are at risk of early menopause.

Various studies have attempted to evaluate the impact of salpingectomy on ovarian function with studies dating back up to 1981 with first ones done on animals. Majority of these studies used the ovarian response after ovarian stimulation for IVF as the study model (Verhulst et al, 199422; Lass et al, 199823; Dar et al, 200024; Strandell et al, 200125; Tal et al, 2002). ${ }^{26}$ Beyth and Winston (1981) ${ }^{27}$ performed microsurgical fimbriectomy in rabbits and observed fewer ovulations on the operated side. McComb and Delbeke $(1984)^{28}$ described in rabbits the effect of surgical division of the anastomotic blood vessels between the ovary and the fimbria on the number of ovulations in that ovary. A significant reduction in the number of ovulations occurred in the experimental ovary compared with the contralateral control ovary in the same animal.

Lass et al (1998) 23 reported that in patients who had undergone unilateral salpingectomy, significantly fewer follicles developed and consequently fewer oocytes were retrieved from the operated side compared with the intact adnexa, although the ovarian volume was not reduced. These results may suggest that a degree of blood flow impairment to the ovary occurred after salpingectomy; this impairment altered follicular development, but not sufficiently to cause ovarian shrinkage.

Chan C et al (2003)12 evaluated ovarian stromal blood flow using 3D power Doppler ultrasonography in 32 patients who had had unilateral salpingectomy for $>3$ months. Two other markers of ovarian function, the antral follicle count and the ovarian volume were evaluated at the same time. There was no difference in all these markers on the ipsilateral side of salpingectomy when compared to the non-operated side. However, they have demonstrated impaired ovarian blood flow and reduced antral follicle count on the operated side shortly after laparoscopic unilateral salpingectomy. This may imply an adverse sub-clinical short-term effect on the ovary after salpingectomy. Chan $\mathrm{C}$ et al have also observed that if the mechanism of reduced ovarian blood flow after sterilisation is due to the interruption of blood supply, the same mechanism applies in salpingectomy which involves more extensive surgery than sterilisation. Furthermore, the decreased antral follicle count was further evidence that vascular supply was jeopardised.

Thus, the above four studies contradict the findings in our study. Following are the studies which correlate to our findings.

Sezik Mekin et al 2007.29 They investigated the effect of total salpingectomy during hysterectomy in a small sample of 12 patients compared to other 12 treated by partial salpingectomy. In their patients mean FSH, LH, estradiol values and ovarian volume were unchanged after both of the techniques. However, mean pulsatility index, resistance index and systole/diastole (S/D) ratio were significantly decreased in both groups compared to baseline values and postoperative decline in the mean pulsatility index was more pronounced group with partial salpingectomy. They concluded that complete removal of fallopian tubes during hysterectomy has no advantageous effect on ovarian blood supply. It might be important to protect the ovarian blood supply as much as possible, while performing hysterectomy in the reproductive period.

In 2013, Morelli et al ${ }^{30}$ performed a retrospective comparison of women who underwent hysterectomy without salpingectomy to women who underwent hysterectomy with salpingectomy when ovarian preservation was maintained. This study had a larger number of patients (79 in each group) and found no significant difference in $\mathrm{AMH}, \mathrm{FSH}$, antral follicle count, mean ovarian diameters or peak systolic velocity between groups.

These findings are also consistent with studies examining ovarian response to IVF after salpingectomy for hydrosalpinges, most of which have shown no deleterious effects on IVF outcomes. ${ }^{31}$ Ovarian response to gonadotropin during IVF treatment is commonly used to evaluate ovarian function after salpingectomy. In two retrospective casecontrolled studies (Verhulst et al, 199422; Tal et al 200226), no difference in ovarian response after gonadotropin stimulation during IVF treatment could be found between patients with and without salpingectomy. In order to limit bias introduced by the control group, Dar et al (2000) ${ }^{24}$ and Strandell et al (2001) ${ }^{25}$ used the patients themselves as the controls, and compared the ovarian response to gonadotropin during IVF treatment before and after salpingectomy. There was again no difference demonstrated.

While removal of the ovaries and fallopian tubes clearly results in reduced risk of pelvic serous cancers, ${ }^{32}$ we do not yet know if same applies to salpingectomy alone with ovarian retention. If indeed salpingectomy resulted in decreased ovarian function, then the decision to remove the fallopian tubes at the time of hysterectomy would involve a riskbenefit calculation similar to the discussion of adnexectomy. But if removing the fallopian tubes has no significant impact on ovarian function and does not complicate the hysterectomy, it would leave little reason not to perform salpingectomy routinely. An additional benefit would include avoidance of future operations for benign conditions of the fallopian tube such as hydrosalpinx, paratubal cyst or tubal prolapse. 33 If current research regarding the role of the 
fallopian tube in the pathogenesis of pelvic serous cancers continues to expand, the argument to consider prophylactic salpingectomy at the time of hysterectomy, tubal sterilisation or other elective abdominal and pelvic surgery grows stronger.

Our study does show that there is no significant affection of ovarian function due to salpingectomy and removal of the tubes rather than the ovaries could be efficient in preventing HGSC, potentially avoiding issues of long-term surgical complication and hormonal function. The British Columbia Ovarian Cancer Prevention Project ${ }^{34}$ encourages prophylactic salpingectomy and estimates up to $50 \%$ reduction in ovarian cancer deaths after 20 years up to $20 \%$ through salpingectomy at time of hysterectomy, up to $20 \%$ through salpingectomy instead of tubal ligation and up to $20 \%$ through risk-reducing bilateral salpingo-oophorectomy in patients with BRCA mutations. Salpingectomy in both the average and high-risk populations could therefore prevent HGSC by eliminating the site of initiation and interrupting spread of potentially cancerous cells to the ovarian/peritoneal surfaces. Salpingectomy may also reduce the incidence of the 2 next most common subtypes, endometrioid and clear cell carcinoma by blocking the passageway linking the lower genital tract to the peritoneal cavity that enables ascension of endometrium and factors that induce local inflammation. The implementation of salpingectomy therefore promises to significantly impact on ovarian cancer incidence and outcomes.

Therefore, based on our study and other recent studies, prophylactic salpingectomy during hysterectomy should be advocated routinely.

\section{CONCLUSION}

At the end of 6 months postoperatively there was no significant rise in the KI, FSH levels and ovarian volumes in the group undergoing TAH with Salpingectomy and there was no significant difference between the two groups with respect to each variable. So, we conclude that salpingectomy does not significantly affect the function of the intact ovaries after TAH-BLS.

\section{REFERENCES}

[1] Kindelberger DW, Lee Y, Miron A, et al. Intraepithelial carcinoma of the fimbria and pelvic serous carcinoma: evidence for a causal relationship. Am J Surg Pathol 2007;31(2):161-9.

[2] Callahan MJ, Crum CP, Medeiros F, et al. Primary fallopian tube malignancies in BRCA- positive women undergoing surgery for ovarian cancer risk reduction. J Clin Oncol 2007;25(25):3985-90.

[3] Kurman RJ, Shih IeM. The origin and pathogenesis of epithelial ovarian cancer: a proposed unifying theory. Am J Surg Pathol 2010;34(3):433-43.

[4] Crum CP, Drapkin R, Kindelberger D, et al. Lessons from BRCA: the tubal fimbria emerges as an origin for pelvic serous cancer. Clin Med Res 2007;5(1):35-44.

[5] Manchanda R, Abdelraheim A, Johnson $M$, et al. Outcome of risk-reducing salpingo-oophorectomy in BRCA carriers and women of unknown mutation status. BJOG 2011;118(7):814-24.
[6] Powell CB, Chen LM, McLennan J, et al. Risk-reducing salpingo-oophorectomy (RRSO) in BRCA mutation carriers: experience with a consecutive series of 111 patients using a standardized surgical pathological protocol. Int J Gynecol Cancer 2011;21(5):846-51.

[7] Bag TS, Kyal A, Saha DP, et al. Isoflavone in postmenopausal women-are they really effective? A prospective case control study. NJOG 2012;7(1):11-4.

[8] Kupperman HS, Blatt MH, Wiesbader $\mathrm{H}$, et al. Comparative clinical evaluation of estrogenic preparations by the menopausal and amenorrheal indices. J Clin Endocrinol Metab 1953;13(6):688-703.

[9] White CP, Hitchcock CL, Vigna YM, et al. Fluid retention over the menstrual cycle: 1-year data from the prospective ovulation cohort. Obstet Gynecol Int 2011;2011:138451.

[10] Sessume JV, Murphy DP. Hysterectomy and the artificial menopause. Sur Gynecol Obstet 932;55:2869.

[11] Cattanach J. Oestrogen deficiency after tubal ligation. Lancet 1985;1(8433):847-9.

[12] Chan CC, Ng EH, Ho PC, et al. Impaired ovarian blood flow and reduced antral follicle count following laparoscopic salpingectomy for ectopic pregnancy. Human Reproduction 2003;18(10):2175-80.

[13] Repasy I, Lendvai V, Koppan A, et al. Effect of the removal of the fallopian tube during hysterectomy on ovarian survival: the orphan ovary syndrome. Eur J Obstet Gynecol Reprod Biol 2009;144(1):64-7.

[14] Nahás EAP, Pontes A, Nahas-Neto J, et al. Effect of total abdominal hysterectomy on ovarian blood supply in women of reproductive age. J Ultrasound Med 2005;24:169-174.

[15] Nouh A, El Behery M, Alanwar A, et al. Total salpingectomy during abdominal hysterectomy preserves ovarian blood flow and function. Webmed Central Obstetrics and Gynaecology 2010;1(9):WMC00707.

[16] Derksen JG, Brölmann HA, Wiegerinck MA, et al. The effect of hysterectomy and endometrial ablation on follicle stimulating hormone (FSH) levels up to 1 year after surgery. Maturitas 1998;29(2):133-8.

[17] Souza AZ, Fonseca AM, Izzo VM, et al. Ovarian histology and function after total abdominal hysterectomy. Obstet Gynecol 1986;68(6):847-9.

[18] Siddle N, Sarrel P, Whitehead M. The effect of hysterectomy on the age at ovarian failure: identification of a subgroup of women with premature loss of ovarian function and literature review. Fertil Steril 1987;47(1):94-100.

[19] Bhattacharya S, Mollison J, Pinion S, et al. A comparison of bladder and ovarian function two years following hysterectomy or endometrial ablation. $\mathrm{Br} \mathrm{J}$ Obstet Gynaecol 1996; 103:898-903.

[20] Deng CY, Tang DM, Yu Q, et al. Effect of premenopausal hysterectomy on ovarian function. Zhongguo Yi Xue Ke Xue Yuan Xue Bao 2002;24(6):639-42.

[21] Ahn EH, Bai SW, Song CH, et al. Effect of hysterectomy on conserved ovarian function. Yoseni Med J 2002;43(1):53-8. 
[22] Verhulst G, Vandersteen N, Steirteghem ACV, et al. Bilateral salpingectomy does not compromise ovarian stimulation in an in-vitro fertilization/embryo transfer programme. Hum Reprod 1994;9(4):624-8.

[23] Lass A, Ellenbogen A, Croucher C, et al. Effect of salpingectomy on ovarian response to superovulation in an in vitro fertilization-embryo transfer program. Fertil Steril 1998;70(6):1035-8.

[24] Dar P, Sachs GS, Strassburger D, et al. Ovarian function before and after salpingectomy in artificial reproductive technology patients. Hum Reprod 2000;15(1):142-4.

[25] Strandell A, Lindhard A, Waldenstrom U, et al. Prophylactic salpingectomy does not impair the ovarian response in IVF treatment. Hum Reprod 2001;16(6):1135-9.

[26] Tal J, Paltieli Y, Korobotchka R, et al. Ovarian function after laparoscopic salpingectomy 2179.

[27] Beyth Y, Winston RML. Ovum capture and fertility following microsurgical fimbriectomy in the rabbit. Fertil Steril 1981;35(4):464-72.

[28] McComb P, Delbeke L. Decreasing the number of ovulations in the rabbit with surgical division of the blood vessels between the fallopian tube and ovary. J Reprod Med 1984;29(11):827-9.
[29] Sezik M, Ozkaya O, Demir F, et al. Total salpingectomy during abdominal hysterectomy: effects on ovarian reserve and ovarian stromal blood flow. J Obstet Gynaecol Res 2007;33(6):863-9.

[30] Morelli M, Venturella R, Mocciaro R, et al. Prophylactic salpingectomy in premenopausal low-risk women for ovarian cancer: primum non nocere. Gynecol Oncol 2013;129(3):448-51.

[31] Almog B, Wagman I, Bibi G, et al. Effects of salpingectomy on ovarian response in controlled ovarian hyperstimulation for in vitro fertilization: a reappraisal. Fertil Steril 2011;95(8):2474-6.

[32] Finch A, Beiner M, Lubinski J, et al. Salpingooophorectomy and the risk of ovarian, fallopian tube, and peritoneal cancers in women with a BRCA1 or BRCA2 mutation. JAMA 2006;296(2):185-92.

[33] Dietl J, Wischhusen J, Hausler SF. The postreproductive fallopian tube: better removed? Hum Reprod 2011;26(11):2918-24.

[34] http://www.ovcare.ca. 